Vol. 39(2), pp. 198-212, Dec. 2020

ISSN 1821-536X (print)

ISSN 2619-8789 (electronic)
Tanzania Journal of Engineering and Technology Copyright () 2020 College of Engineering and Technology, University of Dar es Salaam

Full Length Research Paper

\title{
Fermentability of Concentrated Sulfuric acid Hydrolyzates from Aspenwood and Pinewood
}

\author{
1,* Kando K. Janga, ${ }^{2}$ Nils Dyrset, ${ }^{3}$ Karin Øyaas, ${ }^{4}$ Størker T. Moe \\ ${ }^{1}$ Department of Chemical and Mining Engineering, University of Dar es Salaam, \\ Tanzania. \\ ${ }^{2}$ SINTEF Materials and Chemistry, NO-7491 Trondheim, Norway \\ ${ }^{3}$ Paper and Fibre Research Institute, NO-7491 Trondheim, Norway \\ ${ }^{4}$ Norwegian University of Science and Technology (NTNU), Department of Chemical \\ Engineering, NO-7491 Trondheim, Norway \\ *Correspondence author: kandojanga@yahoo.com
}

\begin{abstract}
The fermentability of hydrolyzates derived from two-stage concentrated sulfuric acid hydrolysis of Trembling aspen (Populus tremula) and Scots pine (Pinus sylvestris) were investigated. Three types of hydrolyzates were produced at mild, moderate and high decrystallization severity conditions. Portions of each of the original hydrolyzates were concentrated by vacuum evaporation to increase the sugar fraction to simulate industrial applications. Both sets of hydrolyzates were fermented anaerobically using Saccharomyces cerevisiae ATCC 96581. After 23 hours of fermentation, complete glucose consumption was observed for all the original hydrolyzates, with no signs of inhibition. The ethanol yields from these hydrolyzates ranged from $68 \%$ to $90 \%$ of theoretical value. Fermentation of concentrated aspen hydrolyzates produced at mild or moderate decrystallization severity showed a significant lag phase, associated with relatively high furfural content in the samples (approximately $2 \mathrm{~g} / \mathrm{L}$ ). No lag phase was apparent for aspen produced at high decrystallization severity or pine hydrolyzates. However, furfural had no adverse effect on the maximum ethanol yield. No inhibitory effect of HMF, acetic acid, formic acid or levulinic acid was detected in the concentrated hydrolyzates due to the relatively low concentrations of these compounds. The ethanol yields from concentrated hydrolyzates were above $97 \%$ of theoretical with exception of pine hydrolyzate produced at high severity which had a fairy good yield of $87 \%$. The quantitative analysis of inhibitors and the fermentability investigation showed that both the original and concentrated hydrolyzates from the concentrated sulfuric acid process were readily fermentable, and furfural was singled out as the most important inhibitor in these hydrolyzates.
\end{abstract}

Keywords: Decrystallization; trembling aspen (Populus tremula); scots pine (Pinus sylvestris); concentrated sulfuric acid; hydrolyzate; fermentability; fermentation inhibitors. 


\section{INTRODUCTION}

The use of lignocellulosic biomass as a source of sugars for production of ethanol and other biofuels has been of growing interest due to its abundance, renewability and low cost (Sun and Cheng, 2002; Knauf and Moniruzzaman, 2004). Compared to other saccharification processes, the concentrated acid hydrolysis process is believed to achieve near theoretical biomass-to-sugar yields with fewer degradation products (Schell and Duff, 1996; Miller and Hester, 2007). The near theoretical sugar yields and fewer degradation products are achievable because the process employs lower temperatures and concentrated acids and the reaction time is practically feasible. Although consumption of large quantities of concentrated acids has been a major drawback of this process, the invention of new acid recovery technologies (Nanguneri and Hester 1990; Springfield and Hester 1999; Weydahl, 2010) has renewed interest on this process.

In acid hydrolysis, sugars will degrade to a certain extent during the saccharification process. However, the amount and extent of degradation is significantly influenced by the intensity of the hydrolysis conditions (hydrolysis severity) and the type of biomass Rajan and Carrier, 2014). The most important biomass-derived sugar degradation products in acid hydrolyzates are furans of which furfural and 5-hydroxymethyl furfural (HMF) are of interest as these compounds are usually found in significant quantities (Taherzadeh et al., 1997). Furfural and HMF are toxic to fermenting microorganisms and have been described as the strongest inhibitors to Saccharomyces cerevisiae (Sanchez and Bautista, 1988). Inhibitors can severely affect the fermentation of sugar to ethanol, and as one of the degradation products, they reduce the sugar yield, hence decreasing the overall biomass-to-ethanol conversion efficiency (Badger, 2002). Other fermentation inhibitors in wood hydrolyzates are organic (carboxylic) acids such as acetic acid which is released from the side groups of heteropolymers (acetylated hemicelluloses) during hydrolysis and levulinic and formic acids which results from further degradation of sugars degradation products. Phenolic compounds resulting from lignin degradation and extractives have been described as important inhibitors released into wood hydrolyzates during acid hydrolysis process (Clark and Mackie, 1984). In some cases, inhibitor have to be removed to improve the fermentability (Huang et al., 2020).

In a study by Wayman and Parekh (1987), hydrolyzates from concentrated sulfuric acid hydrolysis of Pinus patula did not show any inhibition to the microorganisms, but the inhibitors levels were not investigated. To the knowledge of this work's authors, the literature addressing the formation of biomassderived sugar degradation products and other inhibitors and the fermentability of hydrolyzates from concentrated acid processes is very limited. On the other hand, such information on dilute acid hydrolyzates is extensively studied (Larsson et al., 1998; Boussaid et al., 1999; Lee et al., 1999; Robinson et al., 2003). In our previous study (Janga et al., 2012), hydrolyzates from concentrated sulfuric acid hydrolysis of aspen and pine were quantitatively analyzed and correlations between decystallization conditions, sugar yields and inhibitor production were established. However, fermenting a number of selected hydrolyzates can give a direct product (hydrolyzate) quality test in terms of fermentability rather than relying on the quantitative 
analysis, since such a test also may show effects of unknown and/or unquantified inhibitors present in the hydrolyzates.

Thus, in this study, inhibitor content and the fermentation characteristics or fermentability (quality) of aspenwood and pinewood hydrolyzates derived from a two-stage concentrated sulfuric acid hydrolysis process are investigated. The hydrolyzates were produced at different decrystallization severities determined by the time, temperature and acid concentration combined together in the generalized severity parameter. The samples were studied at low (original hydrolyzates) and high (concentrated hydrolyzates) sugar and inhibitor concentrations. Fermentability trials were performed using the ethanologenic yeast Saccharomyces cerevisiae ATCC 96581.

\section{MATERIALS AND METHODS}

\section{Lignocellulosic Biomass}

The biomass types considered in this study were the Nordic wood species trembling aspen (Populus tremula) and Scots pine (Pinus sylvestris). The size distribution of the used wood chips and the chemical composition analysis (Table 1) has been described in our previous study (Janga et al., 2012).

Table 1: Chemical composition of aspen and scots pine feedstocks (wt. \% on dry weight basis of original wood)

\begin{tabular}{|c|c|c|c|c|c|c|c|c|c|c|c|}
\hline \multirow{3}{*}{ Feedstock } & \multicolumn{5}{|c|}{ Carbohydrate polymers } & \multirow{2}{*}{\multicolumn{2}{|c|}{ Lignin }} & \multirow{2}{*}{\multicolumn{2}{|c|}{$\begin{array}{l}\text { Low molecular } \\
\text { mass compounds }\end{array}$}} & \multirow{3}{*}{ 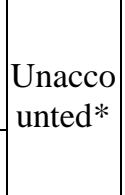 } & \multirow{3}{*}{ Total } \\
\hline & \multicolumn{3}{|c|}{ Hexosans } & \multicolumn{2}{|c|}{ Pentosans } & & & & & & \\
\hline & Glucan & Mannan & Galactan & Xylan & Arabinan & $\mathrm{AIL}^{\mathrm{a}}$ & $\mathrm{ASL}^{\mathrm{b}}$ & Extractives & Ash & & \\
\hline Aspen & 45.6 & 1.8 & 1.7 & 17.9 & 0.5 & 18.6 & 0.6 & 3.1 & 0.5 & 9.7 & 100.0 \\
\hline Pine & 43.6 & 11.3 & 1.5 & 6.4 & 0.9 & 26.1 & 0.3 & 2.3 & 0.5 & 7.1 & 100.0 \\
\hline
\end{tabular}

${ }^{\mathrm{a}}$ Acid insoluble lignin; ${ }^{\mathrm{b}}$ Acid soluble lignin

* Based on literature data, most of the unaccounted to complete $100 \%$ balance is believed to be uronic acids and acetyl content in hemicelluloses.

\section{Microorganism and Media}

\section{Yeast train and seed culture medium}

The microorganism used in this study was the yeast Saccharomyces cerevisiae ATCC 96581, originally isolated from spent sulfite liquor fermentation plant in a pulp mill and is known to utilize and ferment C-6 sugars only (Lindén et al., 1992). The $S$. cerevisiae ATCC 96581 was obtained commercially. The seed culture was prepared by inoculation from a glycerol stock and grown in 250 $\mathrm{mL}$ shaking flasks on a culture medium containing $3 \mathrm{~g} / \mathrm{L}$ yeast extract, $5 \mathrm{~g} / \mathrm{L}$ peptone, $3 \mathrm{~g} / \mathrm{L}$ malt extract and $10 \mathrm{~g} / \mathrm{L}$ glucose (YM-broth) in a shaking incubator overnight at $30{ }^{\circ} \mathrm{C}$ and 200 $\mathrm{rpm}$ before inoculating to the fermentation tube.

\section{Nutrients/mineral medium}

The fermentation medium was synthetic as described by Brandberg et al., 2005, and consisted of.: $\left(\mathrm{NH}_{4}\right)_{2} \mathrm{SO}_{4}(7.5 \mathrm{~g} / \mathrm{L})$, $\mathrm{MgSO}_{4} \cdot 7 \mathrm{H}_{2} \mathrm{O}(0.5 \mathrm{~g} / \mathrm{L}), \mathrm{ZnSO}_{4} \cdot 7 \mathrm{H}_{2} \mathrm{O}$ $(0.2 \mathrm{~g} / \mathrm{L})$, yeast extract $(1.0 \mathrm{~g} / \mathrm{L})$, $\mathrm{KH}_{2} \mathrm{PO}_{4}(3.5 \mathrm{~g} / \mathrm{L})$, MES $(4.0 \mathrm{~g} / \mathrm{L})$, trace minerals and vitamins. Trace minerals were: $\quad \mathrm{FeSO}_{4} \cdot 7 \mathrm{H}_{2} \mathrm{O} \quad(600 \mathrm{mg} / \mathrm{L})$, $\mathrm{ZnSO}_{4} \cdot 7 \mathrm{H}_{2} \mathrm{O}(150 \mathrm{mg} / \mathrm{L}), \mathrm{MnSO}_{4} \cdot \mathrm{H}_{2} \mathrm{O}$ $(15 \mathrm{mg} / \mathrm{L}), \mathrm{CuSO}_{4} \cdot 5 \mathrm{H}_{2} \mathrm{O}(5.25 \mathrm{mg} / \mathrm{L})$, 
$\mathrm{NaMoO}_{4} \cdot \mathrm{H}_{2} \mathrm{O}(5.25 \mathrm{mg} / \mathrm{L}), \mathrm{CoCl}_{2} \cdot 6 \mathrm{H}_{2} \mathrm{O}$ $(1.5 \mathrm{mg} / \mathrm{L})$, boric acid $\left(0.38 \mathrm{mg} \cdot \mathrm{L}^{-1}\right)$ and vitamins were: Ca-pantothenate (30 $\mathrm{mg} / \mathrm{L})$, biotin $(4.5 \mathrm{mg} / \mathrm{L})$, thiamine- $\mathrm{HCl}$ $(2.25 \mathrm{mg} / \mathrm{L})$.

\section{Preparation of Hydrolyzates by the Two-stage Concentrated Sulfuric Acid Hydrolysis Process}

The hydrolyzates used in this study were produced by the two-stage concentrated sulfuric acid hydrolysis process consisting of one decrystallization stage and one hydrolysis stage. Two sets of hydrolyzates were used for studying the fermentation characteristics. The first set of hydrolyzates called the original (unconcentrated) hydrolyzates was produced directly from the two-stage concentrated sulfuric acid hydrolysis as described by Janga et al. (2012). A relatively high liquid-to-wood ratio of $15: 1 \quad(\mathrm{w} / \mathrm{w}) \quad$ was used during decrystallization due to mixing limitations in the laboratory. However, industrially relevant acid-to-wood ratios of down to $1: 1$ can be achieved by the use of efficient mixing equipment such as twin-screw extruder reactor (Miller and Hester, 2007).

The decrystallization condition intensities (severities) were categorized as mild, moderate and high severity based on glucose recovery (Table 2) to describe the extent of reactions at the decrystallization stage in the two-stage concentrated sulfuric acid hydrolysis. The severity $\left(\mathrm{CSF}_{\mathrm{SA}}\right)$ expressed as the logarithm of generalized severity parameter $\left(\mathrm{R}_{\mathrm{OH}}\right)$ [Equations (1) and (2)] combines the reaction temperature, time and acid concentration in a single reaction ordinate to describe the hydrolysis effect on carbohydrate polymer solubilization or sugar yields (Abatzoglou et al., 1992). The parameters in $\mathrm{R}_{\mathrm{OH}}$ describing the effect of temperature $(\omega)$ and acid effect $(\lambda)$ at the decrystallization stage for concentrated sulfuric acid hydrolysis of aspen and pine has been estimated in our previous study (Janga et al., 2011).

Generalized Severity parameter is given by equation (1).

$$
R_{O H}=\int_{0}^{t} \exp \left(\frac{C-C_{r e f}}{\lambda C_{r e f}}\right) \exp \left(\frac{T-T_{r e f}}{\omega}\right) d t
$$

Where: $\mathrm{C}$ and $\mathrm{C}_{\mathrm{ref}}$ are the acid concentration and reference acid concentration in $\mathrm{mol} / \mathrm{L}$ or $\% \mathrm{w} / \mathrm{w}, \mathrm{T}$ and $\mathrm{T}_{\text {ref }}$ are the temperature and reference temperature in $\mathrm{K}$, respectively.

The severity for concentrated sulfuric acid hydrolysis is given by equation (2).

$$
\mathrm{CSF}_{\mathrm{SA}}=\ln \left(\mathrm{R}_{\mathrm{OH}}\right)
$$

Where for glucose in aspen: $\lambda=0.12 ; \omega$ $=15.82$; glucose in pine: $\lambda=0.21 ; \omega=$ 20.26 (Janga et al., 2011)

The second set of hydrolyzates called concentrated hydrolyzates was obtained by concentrating a portion of the original hydrolyzate by vacuum evaporation in order to increase the concentration of sugars and other reaction products, e.g. inhibitors and sugar degradation products in an attempt to simulate industrial hydrolysis at high dry matter content. 
Table 2: Decrystallization conditions and chemical composition of the original hydrolyzates derived from a two-stage concentrated sulfuric acid hydrolysis of aspen and pine

\begin{tabular}{|c|c|c|c|c|c|c|c|c|c|c|c|c|c|c|c|c|}
\hline \multirow{3}{*}{ Sample } & \multicolumn{3}{|c|}{$\begin{array}{c}\text { Decrystallization } \\
\text { conditions }\end{array}$} & \multirow{2}{*}{\multicolumn{2}{|c|}{ Severity }} & \multirow{2}{*}{\multicolumn{5}{|c|}{$\begin{array}{c}\text { Monosaccharides } \\
\text { concentration } \\
(\mathrm{g} / \mathrm{L})\end{array}$}} & \multirow{3}{*}{$\begin{array}{c}\text { Total } \\
\text { sugar } \\
\text { yield } \\
(\mathrm{g} \\
/ 100 \\
\mathrm{~g} \\
\mathrm{~d} . \mathrm{w})\end{array}$} & \multirow{2}{*}{\multicolumn{5}{|c|}{$\begin{array}{l}\text { Inhibitor concentration } \\
(\mathrm{g} / \mathrm{L})\end{array}$}} \\
\hline & \multirow{2}{*}{$\begin{array}{l}\text { Temp } \\
\left({ }^{\circ} \mathrm{C}\right)\end{array}$} & \multirow{2}{*}{$\begin{array}{l}\text { Time } \\
(\mathrm{min})\end{array}$} & \multirow{2}{*}{$\begin{array}{l}\text { Acid } \\
\text { conc. } \\
\text { (wt. } \\
\%)\end{array}$} & & & & & & & & & & & & & \\
\hline & & & & $\mathrm{CSF}_{\mathrm{S} A}$ & Severity & Glc & Xyl & Gal & Ara & Man & & HMF & Furf. & Form & $\begin{array}{c}\mathrm{AcO} \\
\mathrm{H}\end{array}$ & Lev \\
\hline Aspen $_{\mathrm{Hi}}$ & 53 & 120 & 73 & 5.44 & High & 7.12 & 1.00 & 0.08 & 0.05 & 0.26 & 48.49 & 0.03 & 0.16 & 0.67 & 1.32 & 0.50 \\
\hline Aspen ${ }_{\text {Mod }}$ & 35 & 60 & 68 & 3.22 & Moderate & 7.79 & 2.57 & 0.09 & 0.07 & 0.44 & 58.50 & 0.03 & 0.38 & 0.95 & 1.71 & 0.52 \\
\hline Aspen $_{\text {Mil }}$ & 20 & 60 & 65 & 2.04 & Mild & 4.86 & 2.38 & 0.10 & 0.07 & 0.40 & 39.76 & 0.02 & 0.40 & 0.92 & 1.77 & 0.42 \\
\hline Pine $_{\mathrm{Hi}}$ & 53 & 120 & 80 & 6.41 & High & 4.19 & 0.04 & 0.13 & 0.00 & 0.53 & 30.62 & 0.03 & 0.01 & 0.94 & 1.52 & 1.25 \\
\hline Pine $_{\text {Mod }}$ & 35 & 60 & 72 & 3.78 & Moderate & 8.95 & 0.77 & 0.31 & 0.15 & 2.22 & 70.64 & 0.04 & 0.12 & 0.59 & 0.92 & 0.62 \\
\hline Pine $_{\text {Mil }}$ & 20 & 60 & 65 & 2.04 & Mild & 3.30 & 0.83 & 0.34 & 0.17 & 2.23 & 35.05 & 0.02 & 0.17 & 0.51 & 0.95 & 0.33 \\
\hline
\end{tabular}

Glc-Glucose; Xyl-Xylose; Gal-Galactose; Ara-Arabinose; Man-Mannose, HMF-5hydroxymethylfurfural, Furf.- Furfural; Form.-Formic acid; Lev.-Levulinic acid; AcOH.Acetic acid

\section{Concentrating of Hydrolyzates Derived From a Two-stage Concentrated Sulfuric Acid Hydrolysis by Vacuum Evaporation}

The dilute sugar solutions resulting from the two-stage concentrated sulfuric acid hydrolysis process (Table 2) were concentrated in order to increase the concentrations of all reaction products. The neutralized hydrolyzates were evaporated under vacuum (- 0.8 bar) in a rotating vacuum rotavapor (Heidolph VV 2000) set at $120 \mathrm{rpm}$ and the water bath temperature kept at $60^{\circ} \mathrm{C}$. About $120 \mathrm{~mL}$ of a dilute sugar solution was evaporated under vacuum to approximately $20 \pm 2.5 \mathrm{~mL}$. After concentration, the hydrolyzates were analyzed again by HPLC. Since furfural was lost during the vacuum concentration process, it was replenished after concentrating the hydrolyzates. Both the sugars and inhibitors were concentrated by a factor of about $5-6$ indicating about 400 - 500\% percent increase in sugars and inhibitors concentration (Table 3) as compared to the original hydrolyzates in Table 2.

\section{Fermentation of Hydrolyzates}

An anaerobic fermentation process was carried out in $20 \mathrm{~mL}$ fermentation tubes incubated at $30{ }^{\circ} \mathrm{C}$ without shaking. The tubes had a septum lid which was pierced with a syringe needle during sampling without opening the tube. The volumes were $1.5 \mathrm{~mL}$ of the nutrients' medium and $0.1 \mathrm{~mL}$ of the yeast inoculum, and $13.4 \mathrm{~mL}$ of the hydrolyzate to make a total working volume of $15 \mathrm{~mL}$ (de Albuquerque Wanderley et al., 2014). All hydrolyzates were filter-sterilized through a $0.2 \mu \mathrm{m}$ filter before inoculation, and fermentation was initiated by adding the inoculum to the tube already filled with the hydrolyzate and the nutrients' medium. Before 
incubation $1 \mathrm{~mL}$ of the sample was taken, and after incubation, a series of 1 $\mathrm{mL}$ aliquots were sampled at a constant time interval until no more glucose was left. Before sampling the tubes were shaken and the sampled aliquots were centrifuged and later stored at $-4^{\circ} \mathrm{C}$ for sugar and ethanol quantitative analysis.

\section{Analyses of Hydrolyzates and Fermentation Broths}

Monosaccharides (glucose, xylose, galactose, mannose and arabinose) in the original and concentrated hydrolyzates were separated on an anion-exchange 4 $\times 250 \mathrm{~mm}$ CarboPac PA1 analytical column at $30^{\circ} \mathrm{C}$. The eluate was $1.5 \mathrm{mM}$ $\mathrm{NaOH}$ at an isocratic flowrate of 1 $\mathrm{mL} / \mathrm{min}$. The system consisted of Dionex ICS-5000 HPLC and ICS-5000 ED electrochemical detector (Dionex Corp., USA).

The concentration of glucose and ethanol in the fermentation broth and inhibitors in the original and concentrated hydrolyzates was analyzed on the Shimadzu HPLC system (Kyoto, Japan). Ethanol concentration in the fermented broth and sugar degradation products in the original and concentrated hydrolyzates were quantified using an Aminex HPX-87H column (Bio-Rad, Hercules, CA, USA) in line with a Cation-H guard column (Biorad 1250129). A $5 \mathrm{mM}$ amount of sulfuric acid was used as a mobile phase at an isocratic flow rate of $0.6 \mathrm{~mL} / \mathrm{min}$ and column temperature of $65^{\circ} \mathrm{C}$. Furfural, 5-hydroxymethylfurfural (HMF), and levulinic acid were detected at $280 \mathrm{~nm}$ while acetic acid and formic acid were detected at $210 \mathrm{~nm}$ on a ultraviolet (UVVIS) absorbance detector (Shimadzu SPD-6AV). Glucose was separated on a Lead $\left(\mathrm{Pb}^{2+}\right)$ cation-exchange resin column (Aminex HPX-87P, Bio-Rad, USA) at $85^{\circ} \mathrm{C}$ with deionized water as an eluent at a flow rate of $0.6 \mathrm{~mL} / \mathrm{min}$.
Both glucose and ethanol were detected by a refractive index (RI) detector (Shimadzu RID-6A).

\section{Fermentation Characterization}

The important fermentation parameters used to characterize and assess the fermentation characteristics of hydrolyzates were maximum ethanol yield $\left(\mathrm{Y}_{\mathrm{EtOH}}\right)$, volumetric ethanol productivity $\left(\mathrm{Q}_{\mathrm{EtOH}}\right)$ and glucose utilization rate $\left(\mathrm{G}_{\mathrm{r}}\right)$. The maximum ethanol yield indicated the sugars-toethanol conversion efficiency, and was calculated based on the initial concentration of total C-6 sugars/fermentable sugars (glucose, mannose and galactose) in the broth as grams of ethanol produced per grams of hexoses because $S$. cerevisiae ATCC 96581 can only ferment hexoses. Equation (3) was used to calculate the theoretical maximum ethanol yield based on hexoses (de Albuquerque Wanderley et al., 2014, Vogel et al., 2011).

$Y_{E t O H}(\%)=\frac{E(g)}{H(g) \times 0.511} \times 100 \ldots \ldots$

Where $E$ and $H$ are the maximum amount of ethanol produced in the fermentation broth $(\mathrm{g})$ and the initial hexose concentration in the hydrolyzate $(\mathrm{g})$, respectively. Coefficient 0.511 is the stoichiometric yield of ethanol from hexoses. The volumetric ethanol productivity $\left(\mathrm{Q}_{\mathrm{EtOH}}\right)$ determines the capital investment cost in terms of size and cost of the fermenter, and was calculated as the ethanol concentration produced $(\mathrm{g} / \mathrm{L})$ divided by fermentation time (hours) taken to reach that ethanol concentration. The glucose consumption rate was calculated as the amount of glucose utilized $(\mathrm{g} / \mathrm{L})$ per time (hrs). Lag time (LT) is also used to characterize the fermentability. 


\section{RESULTS AND DISCUSSION}

\section{Two-stage Concentrated Sulfuric Acid Hydrolysis of Pine and Aspen}

The decrystallization conditions and the chemical compositions of the original aspen and pine hydrolyzates produced from the two-stage concentrated sulfuric acid hydrolysis are shown in Table 2 .

It can be seen from the data that the original hydrolyzates had quite low sugar concentrations due to dilution caused by high acid/wood ratio, since the monosaccharide yields were fairly high. Both aspen and pine hydrolyzates produced at moderate severity had the best monosaccharides yields with the pine hydrolyzates approaching near theoretical yield values. The correlation between glucose and HMF concentration in the original hydrolyzates and that between xylose and furfural are shown on Figure 1.

A fairly good but weak linear correlation exist between the glucose and HMF yields (Figure 1A). The lower correlation coefficient in glucose-HMF profile can be explained by the presence of other hexoses (mannose, which makes up a significant fraction of the wood sugars, and galactose) degrading to form HMF and, more importantly, the instability of HMF under acidic hydrolysis conditions (Lewkowski, 2001) forming secondary degradation. A very strong linear correlation was observed between xylose and furfural yields (Figure 1B). The high correlation coefficient in the xylose-furfural profile can be explained by the high fraction of xylose in pentoses as compared to arabinose, which can degrade to furfural and the high stability of furfural towards further degradation to secondary degradation products under acidic hydrolysis conditions (Dunlop, 1948; Lehnen et al., 2001). Table 2 also clearly shows that aspen hydrolyzates had relatively high levels of furfural as compared to pine hydrolyzates. This was anticipated due to the high xylan content in aspen and xylose's vulnerability to degradation at acidic hydrolysis conditions.
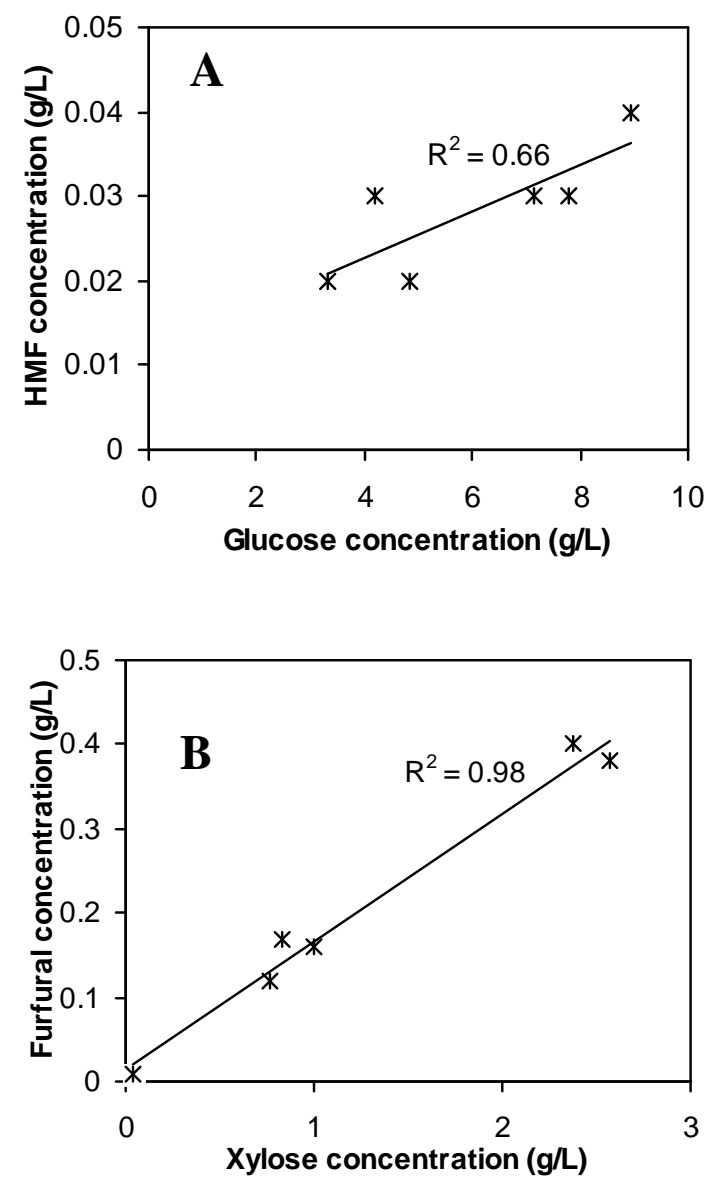

Figure 1: Correlation between initial monosaccharides concentration and degradation products in original hydrolyzates of aspen and pine. (A) glucose against HMF and (B) xylose against furfural

\section{Fermentation of the Original Hydrolyzates}

The results of fermentation of the original hydrolyzates from aspen and pine are shown in Figure 2. The glucose utilization and ethanol production trends show that hydrolyzates produced at all severities were readily fermentable. 
Despite the differences in initial sugar concentrations, complete glucose utilization were observed after 23 hours for all aspen (Figure 2A) and pine (Figure 2B) hydrolyzates. The glucose consumption rate calculated over the fermentation period of 23 hours seemed to depend largely on the initial glucose concentration in the hydrolyzates and increased as the initial glucose concentration increased. A similar observation on increase in fermentation rate as a function of initial hexoses concentration has been reported by Robinson et al. (2003). The maximum ethanol concentration was strongly positive linearly correlated $\left(\mathrm{R}^{2}=0.96\right)$ to the initial hexoses concentration. The maximum ethanol produced in pine hydrolyzates was relative higher than in aspen due to the presence of mannose and galactose, which are also utilized by S. cerevisiae ATCC 96581 as a carbon source after glucose utilization. The ethanol yield data showed that the maximum theoretical ethanol yields in the original hydrolyzates ranged from $68 \%$ to $90 \%$, with hydrolyzates produced at moderate severities showing the best yields of about $85 \%$ (aspen) and $83 \%$ (pine).

The sugar utilization and ethanol production patterns for all three hydrolyzates produced at different severities from aspen (Figure 2A) and pine (Figure 2B) did not show any significant inhibition effect to the microorganisms. This was attributed to the low levels of inhibitors in these hydrolyzates (Table 2).
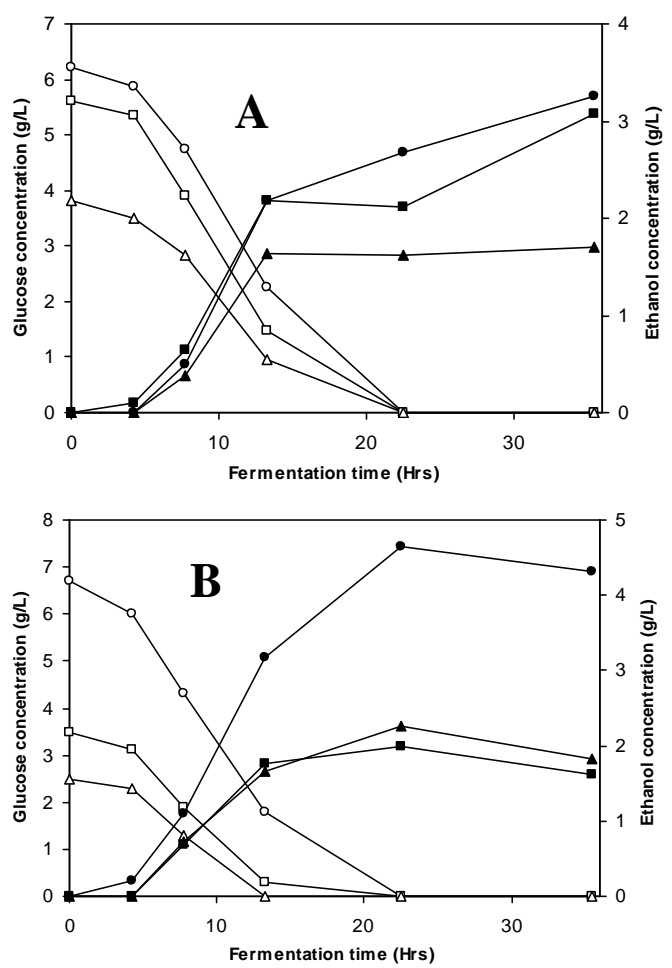

Figure 2: Fermentation profiles of original hydrolyzates derived from two-stage concentrated sulphuric acid hydrolysis. Glucose consumption (open symbols), ethanol production (filled symbols). $\bigcirc$ : Moderate severity, $\triangle$ : Mild severity, $\square$ : High severity. (A) Aspen (B) Pine.

\section{Effect of Inhibitors on the Fermentation of Original Hydrolyzates}

Lack of correlation between inhibitors concentration and maximum ethanol yield and glucose consumption rate suggests the same observation. The reported inhibitory levels of fur fural and HMF to $S$. cerevisiae ATCC 96581 and other ethanologenic yeasts are $2 \mathrm{~g} / \mathrm{L}$ and $3 \mathrm{~g} / \mathrm{L}$, respectively (Sanchez and Bautista, 1988; Boyer et al., 1992; Keating et al., 2006), which is significantly higher than the concentrations found in our hydrolyzates. However, a fairy strong positive linear correlation $\left(\mathrm{R}^{2}=0.84\right)$ was observed between HMF concentration and the volumetric ethanol productivity. This correlation cannot be 
explained precisely by the data gathered in this study due to the low levels of HMF in the hydrolyzates. However, it can probably be related to the ability of $S$. cerevisiae ATCC 96581 to assimilate HMF and convert it to the less toxic compound 5-hydroxymethylfurfuryl alcohol and consequently diminishing its inhibitory effect (Taherzadeh et al., 2000). Product (ethanol) inhibition was not anticipated in these hydrolyzates because the maximum ethanol concentration reached was only $3.3 \mathrm{~g} / \mathrm{L}$ and $4.7 \mathrm{~g} / \mathrm{L}$ in aspen and pine respectively. These ethanol concentration values were far from the ethanol inhibitory level of $S$. cerevisiae ATCC 96581 and other S. cerevisiae species, which can tolerate up to $15 \%$ ethanol concentration (Ghareib et al., 1988; Geng et al., 2010).

\section{Fermentation of Concentrated Hydrolyzates}

The results of chemical composition of the concentrated aspen and pine hydrolyzates after vacuum evaporation process and furfural replenishment and subsequent fermentation are shown in Table 3. The ratio of monosaccharides in the original to concentrated hydrolyzates appeared to be constant. This crosschecking indicated that there was no noticeable sugar degradation during the vacuum concentration process. The highest C-6 sugar concentrations reached about $44.45 \mathrm{~g} / \mathrm{L}$ and $69.33 \mathrm{~g} / \mathrm{L}$ for concentrated samples produced at moderate severity from aspen and pine, respectively. For the most important inhibitors, the highest concentrations were $2.09 \mathrm{~g} / \mathrm{L}, 0.26 \mathrm{~g} / \mathrm{L}$ and $10.07 \mathrm{~g} / \mathrm{L}$ for furfural, HMF and acetic acid, respectively.

The results of fermentation profiles of concentrated hydrolyzates of aspen and pine are shown in Figure 3. The glucose utilization curves show complete glucose consumption after about 60 hours of fermentation in all samples except the aspen sample hydrolyzed at mild severity which showed a markedly increased lag phase (Figure 3A). The ethanol production curves show that the aspen and pine concentrated samples produced at moderate severity had the highest ethanol concentration of about $21.0 \mathrm{~g} / \mathrm{L}$ and $32.0 \mathrm{~g} / \mathrm{L}$, respectively. This was anticipated because these samples had a relatively high concentration of fermentable sugars (hexoses) as compared to those at low and high severity for both aspen and pine. However, all samples at all severities in aspen and pine showed excellent theoretical ethanol yields of above $97 \%$ on hexoses except the pine hydrolyzates at mild severity which had a fairy good yield of $87 \%$. The fermentation characterizing parameters (maximum ethanol yield, glucose consumption rate and volumetric ethanol productivity) for each of the three hydrolyzates in aspen and pine are summarized in Table 3 .

The increase in concentration of the measured inhibitors after concentrating hydrolyzates resulted in a noticeable inhibitory effect revealed by a prolonged fermentation lag phase for concentrated aspen samples hydrolyzed at mild and moderate severities (Figure 3A). No fermentation lag phase was clearly observed for pine concentrated samples of all severities (Figure 3B). A plot of the initial concentrations of inhibitors as function of fermentation lag times (Figure 4) showed that the lag phase increased as furfural concentration increased, with a fairly reasonable, but weak correlation $\left(\mathrm{R}^{2}=0.73\right)$. Inspection of the composition of each of the concentrated samples, which revealed significant fermentation lag times i.e. concentrated aspen samples at mild and moderate severities show that these samples had higher furfural concentration $(\sim 2 \mathrm{~g} / \mathrm{L})$ as compared to 
the rest from aspen and pine. Furfural has been reported to impose strong inhibition to $S$. cerevisiae ATCC 96581 in hydrolyzates at a concentration of about $2 \mathrm{~g} / \mathrm{L}$ (Boyer et al., 1992) and to S. cerevisiae 87 in hydrolyzates at a concentration of about $0.2 \%$ (Sanchez and Bautista, 1988). Apart from acetic acid, which showed a weaker positive correlation $\left(\mathrm{R}^{2}=0.68\right)$ with fermentation lag time, the rest of the individual measured inhibitors shown in Table 3 did not show any inhibition correlation with the lag time. The simple cumulative of all measured inhibitors shown in Table 3 did not show any correlation with the fermentation lag time.

\section{Effect of Inhibitors on the Extent Fermentation of Concentrated Hydrolyzates}

The final or maximum ethanol production was not influenced by the measured inhibitors. This is apparently visible in Figure 3 which shows that despite the increased lag time for aspen samples at mild and moderate severities, fermentation continued to maximum ethanol concentration and complete glucose consumption for all aspen and pine samples of all severities with excellent ethanol theoretical yields. The effect of furfural on ethanol productivity is linked to its effect on the lag phase. Increasing furfural concentration increased the lag time (Figure 4), consequently this resulted in increasing the fermentation time and decreases in volumetric ethanol productivity. The decreased volumetric ethanol productivity upon furfural concentration increase has also been reported by Keating et al. (2006) when fermenting furfural-supplemented synthetic mixtures of hexoses using the yeast $S$. cerevisiae Y-1528 and Larsson et al., 1998 using Baker's yeast (S. cerevisiae).

Table 3: Chemical composition and fermentation of concentrated hydrolyzates from aspen and scots pine

\begin{tabular}{|c|c|c|c|c|c|c|c|c|c|c|c|c|c|c|}
\hline \multirow{2}{*}{ Sample } & \multicolumn{5}{|c|}{$\begin{array}{l}\text { Monosugar concentration } \\
(\mathrm{g} / \mathrm{L})^{\mathrm{a}}\end{array}$} & \multicolumn{5}{|c|}{$\begin{array}{l}\text { Inhibitor concentration } \\
(\mathrm{g} / \mathrm{L})^{\mathrm{a}}\end{array}$} & \multicolumn{4}{|c|}{ Fermentation parameters } \\
\hline & Glc & Xyl & Gal & Ara & Man & HMF & Furf. & Form. & $\mathrm{AcOH}$ & Lev. & LT & $\mathrm{G}_{\mathrm{r}}^{\mathrm{c}}$ & $\mathrm{Y}_{\mathrm{EtOH}}$ & $\mathrm{Q}_{\mathrm{EtOH}}$ \\
\hline Aspen $_{\mathrm{Hi}}$ & 37.02 & 5.57 & 0.39 & 0.27 & 1.41 & 0.17 & 0.87 & 3.34 & 6.09 & 3.00 & 9.00 & 0.51 & 0.50 & 0.29 \\
\hline Aspen $_{\mathrm{Mod}}$ & 41.47 & 14.01 & 0.49 & 0.36 & 2.49 & 0.18 & 2.09 & 5.45 & 10.07 & 3.02 & 32.00 & 0.61 & 0.53 & 0.33 \\
\hline Aspen $_{\text {Mil }}$ & 23.16 & 11.51 & 0.47 & 0.34 & 1.95 & 0.12 & 2.01 & 4.79 & 9.55 & 2.14 & 64.00 & 0.34 & 0.55 & 0.00 \\
\hline Pine $_{\mathrm{Hi}}$ & 20.15 & 0.17 & 0.63 & 0.02 & 2.65 & 0.13 & 0.05 & 4.06 & 5.70 & 6.94 & 9.00 & 0.29 & 0.52 & 0.18 \\
\hline Pine $_{\text {Mod }}$ & 52.30 & 5.02 & 1.92 & 0.95 & 15.11 & 0.26 & 0.70 & 3.66 & 3.27 & 4.00 & 11.50 & 0.73 & 0.52 & 0.50 \\
\hline Pine $_{\text {Mil }}$ & 17.41 & 4.73 & 1.87 & 0.96 & 12.97 & 0.14 & 0.92 & 2.67 & 4.59 & 1.91 & 11.00 & 0.25 & 0.44 & 0.21 \\
\hline
\end{tabular}

${ }^{\mathrm{a}}$ Glc-Glucose; Xyl-Xylose; Gal-Galactose; Ara-Arabinose; Man-Mannose; HMF-5hydroxymethylfurfural, Furf.- Furfural; Form.-Formic acid; Lev.-Levulinic acid; AcOH.Acetic acid.

${ }^{\mathrm{b}} \mathrm{G}_{\mathrm{r}}$ - Glucose consumption rate $\left(\mathrm{g}\right.$ glucose $\left.\cdot \mathrm{L}^{-1} \cdot \mathrm{h}^{-1}\right)$; $\mathrm{Y}_{\mathrm{EtOH}}-$ Maximum ethanol yield $(\mathrm{g}$ ethanol / $\mathrm{g}$ hexoses); $\mathrm{Q}_{\mathrm{EtOH}}$ - Volumetric ethanol productivity $\left(\mathrm{g}\right.$ ethanol $\left.\cdot \mathrm{L}^{-1} \cdot \mathrm{h}^{-1}\right)$; LTLag time (hrs): calculated as time to reach $5 \%$ of maximum ethanol production (Nichols et al., 2010).

${ }^{c}$ Values calculated over a fermentation period of 60 hours. 

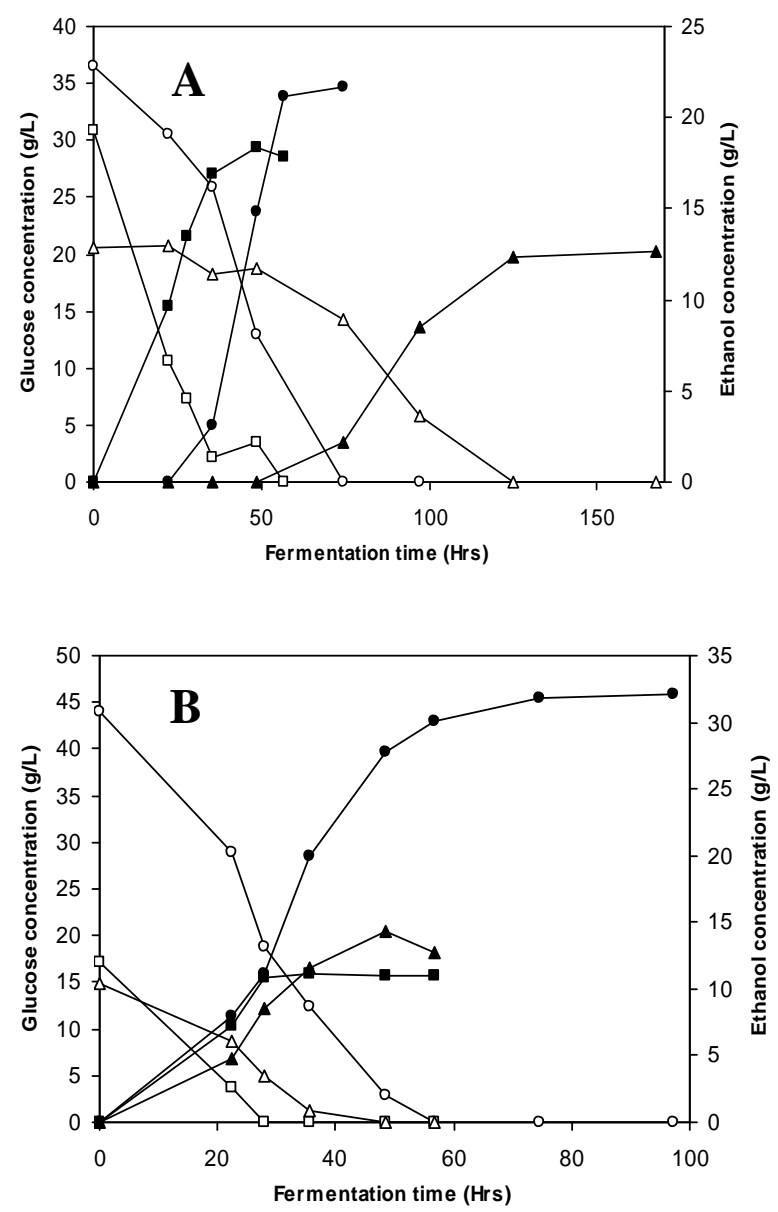

Figure 3: Fermentation profiles of concentrated hydrolyzates. Glucose consumption (open symbols), ethanol production (filled symbols). $\bigcirc$ : Moderate severity, $\triangle$ : Mild severity, $\square$ : High severity. (A) Aspen (B) Pine

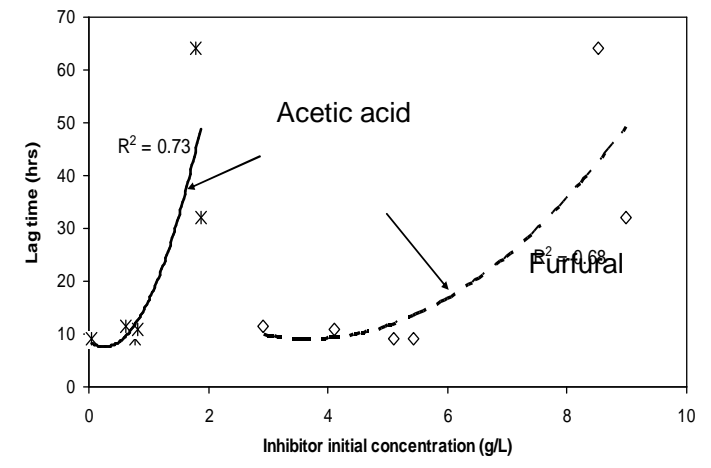

Figure 4: The effect of initial concentration of the measured individual inhibitors on the fermentation lag phase. Data points are from aspen and pine of all severities

The glucose consumption rate was not significantly influenced by the measured inhibitors (Figures 3A and 3B) $(\mathrm{p}=0.05)$. However, the effect of initial substrate (glucose) concentration revealed a much higher influence on glucose consumption rate by showing a strong linear correlation $\left(\mathrm{R}^{2}=0.98\right)$. This strong dependence of glucose consumption rate on the initial substrate concentration could have offset the effect of inhibitors on this fermentation parameter. The results shown by the strong positive linear correlation between HMF and ethanol productivity $\left(\mathrm{R}^{2}=0.83\right)$ and glucose consumption rate $\left(\mathrm{R}^{2}=0.81\right)$ could not be precisely explained by the current data, but could be attributed to the ability of S. cerevisiae ATCC 96581 to assimilated HMF.

\section{Comparison of Fermentability of Original and Concentrated Hydrolyzates}

Direct comparison of glucose utilization rate based on the initial glucose concentration and fermentation periods for complete glucose consumption i.e. 22 hours and 60 hours for original and concentrated hydrolyzates, respectively; showed that there was an increased glucose uptake rate in the concentrated hydrolyzates compared to the original samples for all hydrolyzates. This is usually the anticipated case in the absence of the adverse effects of inhibitors because the glucose uptake rate is directly proportional to the initial substrate concentration. However, in this study the proportionality continued to hold due to the low levels of both measured and unmeasured inhibitors, thus, considered to be less harmful to $S$. cerevisiae ATCC 96581.

Despite an increased concentration of inhibitors in concentrated hydrolyzates compared to the original samples and the differences in final ethanol concentrations, the general fermentation patterns of the original hydrolyzates (Figure 2) and 
concentrated hydrolyzates (Figure 3) were quite similar. Furthermore, it is assumed that the microorganism's sensitivity to inhibition would be increased at higher concentrations of ethanol in the fermentation broths of concentrated hydrolyzates due ethanol stress and synergy with inhibitors, but this effect was not noticeable. These observations suggest three scenarios: Firstly, the observations are attributed to the low levels of the measured and unmeasured inhibitors in the original and concentrated hydrolyzates and their synergy to be harmless to $S$. cerevisiae ATCC 96581. Secondly, the robustness of $S$. cerevisiae ATCC 96581 which is reported to be a high inhibitortolerant strain (Lindén and Hahn-Hägerdal, 1989; Martín and Jönsson, 2003; Brandberg et al., 2004); and thirdly, the reported ability of $S$. cerevisiae ATCC 96581 to assimilate furfural and HMF and convert them to less toxic compounds, hence minimizing their inhibitory effect during fermentation (Taherzadeh et al., 2000; Brandberg et al., 2005).

The furfural concentrations in the original hydrolyzates of aspen at mild and moderate severity were $0.40 \mathrm{~g} / \mathrm{L}$ and 0.38 $\mathrm{g} / \mathrm{L}$, respectively. Although these concentrations were low, there were indications of a slightly increased lag time for these hydrolyzates (Figure 2A). The effect of furfural was clearly visible when the concentration increased to approximately $2 \mathrm{~g} / \mathrm{L}$ in concentrated aspen hydrolyzates (Figure 3A). This suggested that in the presence of other inhibitors, furfural could be slightly toxic to $S$. cerevisiae ATCC 96581 at low levels of up to $1 \mathrm{~g} / \mathrm{L}$. Furfural has been described to be more toxic to yeasts than HMF (Sanchez and Bautista, 1988; Taherzadeh et al., 2000) and its effect is adverse at relatively low concentrations $(<=2 \mathrm{~g} / \mathrm{L})$ as compared to HMF whose inhibitory effect is noticeable only at relatively high concentration (> $3 \mathrm{~g} / \mathrm{L})$ when singly present in hydrolyzates (Pfeifer et al.,
1984; Wikandari et al., 2010).

\section{CONCLUSIONS}

It was concluded that there is high potential of using concentrated sulphuric acid process for ethanol production. It was also concluded that the process can produce clean streams of sugar solutions from various lignocellulosic biomass for ethanol production by $S$. cerevisiae ATCC 96581. Furthermore, it was concluded that furfural was the most important inhibitor in concentrated acid hydrolyzates when fermented by $S$. cerevisiae ATCC 96581.

\section{ACKNOWLEDGEMENTS}

The authors would like to thank the Nordic Energy Research (grant no. 06-renew-I34; New, innovative pretreatment of Nordic wood for cost-effective fuel-ethanol production) together with the Industrial Partners (Statoil ASA, Norske Skog ASA, Borregaard Industries, Norwegian forest owner assoc. and SEKAB) for financial support of this work. Thanks to Professor May-Britt Hägg for enthusiastic support and helpful discussions.

\section{REFERENCES}

Abatzoglou N., Chornet E., Belkacemi K., and Overend R.P. (1992). Phenomenological Kinetics of Complex Systems: The Development of a Generalized Severity Parameter and its Application to Lignocellulosics Fractionation. Chemical Engineering Science, 47(5): 1109-1122 https://doi.org/10.1016/00092509(92)80235-5

Badger P.C. (2002). Ethanol from cellulose: A General Review. In: Janick J. and Whipkey A. editors. Trends in new crops and new uses. Alexandria VA, USA: ASHS Press.

Boussaid A., Robinson J., Cai Y., Gregg D.J. and Saddler J.N. (1999). Fermentability of the hemicellulose- 
derived sugars from steam-exploded softwood (Douglas Fir). Biotechnology and Bioengineering, 64: 284-289.

DOI: $10.1002 /($ sici) $1097-$

0290(19990805)64:3<284::aid-

bit4>3.0.co;2-c

Boyer L.J., Vega J.L., Klasson K.T., Clausen E.C. and Gaddy J.L. (1992). The effects of furfural on ethanol production by Saccharomyces cerevisiae in batch culture, Biomass Bioenergy, 3(2): 41-48. https://doi.org/10.1016/09619534(92)90042-O

Brandberg T., Franzén C.J. and Gustafsson L. (2004). The fermentation performance of nine strains of Saccharomyces cerevisiae in batch and fed-batch cultures in dilute-acid wood hydrolysate. Journal of Bioscience and Bioengineering, 98(2): 122-125. DOI: 10.1016/s1389-1723(04)70252-2

Brandberg T., Sanandaji N., Gustafsson L. and Franzén C.J. (2005). Continuous fermentation of undetoxified dilute acid lignocellulose hydrolysate by Saccharomyces cerevisiae ATCC 96581 using cell recirculation. Biotechnology Progress, 21: 10931101. https://doi.org/10.1021/bp050006y

Clark T. and Mackie K.L. (1984). Fermentation inhibitors in wood hydrolysates derived from the softwood Pinus radiata. Journal of Chemical Technology and Biotechnology B, 34: 101-110.

https://doi.org/10.1002/jctb.280340206

de Albuquerque Wanderley A.C., Soares

M.L. and Gouveia E.R. (2014)

Selection of inoculum size and

Saccharomyces cerevisiae strain for ethanol production in simultaneous saccharification and fermentation (SSF) of sugar cane bagasse. Afr. J. Biotechnol., 13: 2762-2765. DOI: $10.5897 / \mathrm{AJB} 2013.13179$

Dunlop A.P. (1948). Furfural formation and behaviour. Industrial and Engineering Chemistry, 40(2): 204-209. https://doi.org/10.1021/ie50458a006

Geng A., Wangy Z., Lai K.S. and Tan M.W.Y. (2010). Bioenergy II: Comparison of Laboratory and Industrial Saccharomyces cerevisiae Strains for their Stress Tolerance. International Journal of Chemical Reactor Engineering, 8: A87.

Ghareib M., Youssef K.A. and Khalil A.A. (1988). Ethanol tolerance of Saccharomyces cerevisiae and its relationship to lipid content composition. Folia Microbiology, 33: 447-452.

https://doi.org/10.1007/BF02925769

Hames B., Ruiz R., Scarlata C., Sluiter A., Sluiter J. and Templeton D. (2008). Preparation of samples for compositional analysis. National Renewable Energy Laboratory, Golden, CO. USA.

Huang C., Zheng Y., Lin W., Shi Y., Huang G. And Yong Q. (2020). Removal of fermentation inhibitors from pre-hydrolysis liquor using polystyrene divinylbenzene resin. Biotechnology for Biofuels, 13: 188202 https://doi.org/10.1186/s13068020-01828-3

Janga K.K., Hägg M.-B., and Moe S.T. (2012). Influence of acid concentration, temperature, and time on decrystallization in two-stage concentrated sulfuric acid hydrolysis of pinewood and aspenwood: A statistical approach. BioResources, 7(1): 391-411.

Janga K.K., Øyaas K., Hertzberg T. and Moe S.T. (2012). Application of a pseudo-kinetic generalized severity model to the concentrated sulfuric acid hydrolysis of pinewood and aspenwood. 2012, BioResources, 7(3): 2728-2741.

Keating J.D., Panganiban C. and Mansfield S.D. (2006). Tolerance and adaptation of ethanologenic yeasts to lignocellulosic inhibitory compounds. Biotechnology and Bioengineering, 93: 1196-1206. DOI: $10.1002 /$ bit.20838

Knauf M. and Moniruzzaman M. (2004). Lignocellulosic biomass processing: A 
perspective. International Sugar Journal, 106(1263): 147-150.

Larsson S., Palmqvist E., Hahn-Hägerdal B., Tengborg C., Stenberg K., Zacchi G. and Nilvebrant N.O. (1998). The generation of fermentation inhibitors during dilute acid hydrolysis of softwood. Enzyme and Microbial Technology, 24(3-4): 151-159. https://doi.org/10.1016/S01410229(98)00101-X

Lee W.G., Lee J.S., Shin C.S., Park S.C., Chang H.N. and Chang Y.K. (1999). Ethanol production using concentrated oak wood hydrolysates and methods to detoxify. Applied Biochemistry and Biotechnology, 77-79: 547-559. DOI: $10.1385 / \mathrm{abab}: 78: 1-3: 547$

Lehnen R., Saake B. and Nimz H.H. (2001). Furfural and hydroxymethylfurfural as byproducts of FORMACELL pulping. Holzforschung, 55: 199-204. https://doi.org/10.1515/HF.2001.033

Lewkowski J. (2001). Synthesis, chemistry and applications of 5-hydroxymethylfurfural and its derivatives. ArkiVoc, 1: 17-54.

DOI: http://dx.doi.org/10.3998/ark.5550190.0 $\underline{002.102}$

Lindén T. and Hahn-Hägerdal B. (1989). Fermentation of lignocellulose hydrolysates with yeasts and xylose isomerise, Enzyme Microb Technol, 11: 583-589. https://doi.org/10.1016/01410229(89)90086-0

Martín C. and Jönsson L.J. (2003). Comparison of the resistance of industrial and laboratory strains of Saccharomyces and Zygosaccharomyces to lignocellulosederived fermentation inhibitors. Enzyme and Microbial Technology, 32(3-4): 386-395. DOI: 10.1016/S01410229(02)00310-1

Miller S. and Hester R. (2007). Concentrated acid conversion of pine sawdust to sugars. Part I: use of a twinscrew reactor for hydrolysis pretreatment. Chemical Engineering
Communications, 194(1): 85-102. https://doi.org/10.1080/0098644060058 $\underline{6545}$

Nanguneri D.R. and Hester R.D. (1990). Acid/sugar separation using ion exclusion resins: a process analysis and design. Separation Science and Technology, 25: 1829-1842. https://doi.org/10.1080/0149639900805 $\underline{0427}$

Nichols N.N., Dien B.S., Cotta M.A. (2010). Fermentation of bioenergy crops into ethanol using biological abatement for removal of inhibitors. Bioresource Technology, 101(19): 7545-7550.

Pfeifer P.A., Bonn G. and Bobleter O. (1984). Influence of biomass degradation products on the fermentation of glucose to ethanol by Saccharomyces carlsbergensis W34. Biotechnology Letters, 6: 541-546. https://doi.org/10.1007/BF00139999

Rajan K. and Carrier D. J. (2014). Effect of dilute acid pretreatment conditions and washing on the production of inhibitors and on recovery of sugars during wheat straw enzymatic hydrolysis. Biomass and Bioenergy, 62: 222-227. DOI: $10.1016 /$ j.biombioe.2014.01.013

Robinson J., Keating J.D., Mansfield S.D. and Saddler J.N. (2003). The fermentability of concentrated softwood-derived hemicellulose fractions with and without supplemental cellulose hydrolysates. Enzyme and Microbial Technology, 33(6): 757-765. DOI: $\underline{10.1016 / \mathrm{S} 0141-0229(03) 00192-3}$

Sanchez B. and Bautista J. (1988). Efects of furfural and 5-hydroxymethylfurfural on the fermentation of Saccharomyces cerevisiae and biomass production from Candida guillermondii. Enzyme and Microbial Technology, 10(5): 315-318. https://doi.org/10.1016/01410229(88)90135-4

Schell D.J. and Duff B. (1996). Review of pilot plant programs for bioethanol conversion. Handbook of 
Bioethanology: Production and utilization. Ed. Wyman C.E., Taylor \& Francis, Washington, D.C., 381-394.

Sluiter A., Hames B., Ruiz R., Scarlata C., Sluiter J. and Templeton D. (2008a). Determination of ash in biomass. National Renewable Energy Laboratory, Golden, CO. USA.

Sluiter A., Hames B., Ruiz R., Scarlata C., Sluiter J., Templeton D. and Crocker D. (2008b). Determination of structural carbohydrates and lignin in biomass. National Renewable Energy Laboratory, Golden, CO. USA.

Sluiter A., Ruiz R., Scarlata C., Sluiter J. and Templeton D. (2008c). Determination of extractives in biomass. National Renewable Energy Laboratory, Golden, CO. USA.

Springfield R.M. and Hester R.D. (1999). Continuous ion-exclusion chromatography system for acid/sugar separation. Separation Science and Technology, 34(6-7): 1217-1241. https://doi.org/10.1080/0149639990895 1090

Sun Y. and Cheng J. (2002). Hydrolysis of lignocellulosic materials for ethanol production: A review. Bioresource Technology, 83(1): 1-11. https://doi.org/10.1016/S09608524(01)00212-7

Taherzadeh M.J., Eklund R., Gustafsson L., Niklasson C. and Lidén G. (1997). Characterization and Fermentation of
Dilute-Acid Hydrolyzates from Wood. Industrial and Engineering Chemistry Research, 36(11): 4659-4665. https://doi.org/10.1021/ie9700831

Taherzadeh M.J., Gustafsson L., Niklasson C. and Lidén G. (2000). Physiological effects of 5-hydroxymethylfurfural on Saccharomyces cerevisiae. Applied Microbiology and Biotechnology, 53: 701-708.

https://doi.org/10.1007/s002530000328

Vogel K.P., Dien B. S, Jung H.G., Casler M. D., Masterson S. D., Mitchell R. B., (2011). Quantifying Actual and Theoretical Ethanol Yields for Switchgrass Strains Using NIRS Analyses. Bioenerg. Res., 4: 96-110. DOI 10.1007/s12155-010-9104-4

Wayman M. and Parekh S.R. (1987). Hydrolysis and fermentation of African pine. Biotechnology Letters, 9: 445446.

Weydahl K.R. (2010). Method of Production of Alcohol. WIPO Patent Application, WO/2010/038021.

Wikandari R., Millati R., Syamsiyah S., Muriana R. and Ayuningsih Y. (2010). Effect of furfural, hydroxymethylfurfural and acetic acid on indigenous microbial isolate for bioethanol production. Agricultural Journal, 2: 105-109. DOI: 10.3923/aj.2010.105.109 